\title{
Mitigasi Kecelakaan Kapal di Pelawangan Pantai Pancer Kecamatan Puger Kabupaten Jember
}

\author{
Muammar Kadhafi, Mochamad Edoward Ramadhan, Hari Arbiantara \\ Jurusan Teknik Mesin, Fakultas Teknik, Universitas Jember \\ muammar.kadhafil@unej.ac.id
}

\begin{abstract}
Abstrak
Profesi nelayan merupakan profesi yang sangat beresiko karena melakukan aktifitas dilaut yang kondisinya sangat dinamis, ditambah kondisi gelombang laut pantai selatan yang cukup tinggi. Salah satu kecelakaan kapal nelayan di Pantai Puger Jember terjadi pada Juli 2018 yang menyebabkan 9 orang nelayan meninggal dunia. Disisi lain, mayoritas nelayan merupakan kepala keluarga yang harus menafkahi anak, istri dan keluarganya. Ketika kepala keluarga meninggal dunia, maka akan menyebabkan terjadinya masalah-masalah lain sebagai persoalan turunannya seperti kemiskinan dan lain sebagainya. Penyadaran akan pentingnya aspek keselamat kerja dilakukan dalam bentuk kegiatan sosialisasi kepada masyarakat nelayan meliputi presentasi dan diskusi, pembagian alat keselamatan berupa pelampung dan simulasi secara langsung dilapangan guna mengetahui apakah para nelayan menerapkan pengetahuan yang diberikan dengan baik.
\end{abstract}

Kata Kunci: Puger, kecelakaan kapal, keselamatan, nelayan.

\begin{abstract}
A fishermen's profession is very risky because they perform activities in the sea, which can be dynamic; additionally, the south coast sea waves can be quite high. A fishing boat accident on Puger Jember Beach occurred in July 2018, and left nine fishermen dead. The majority of fishermen are family heads who have to provide for their children, wives, and families. When the head of the family dies, it will cause other derivative problems such as poverty. Awareness of the importance of work safety aspects is carried out in the form of socialization activities within fishing communities. These activities include presentations and discussions, the distribution of safety equipment in the form of buoys, and simulations directly in the field to find out whether the fishermen properly apply the knowledge provided.
\end{abstract}

Keywords: Puger, boat accident, safety, fisherman.

\section{PENDAHULUAN}

Profesi nelayan merupakan profesi yang sangat beresiko karena melakukan aktifitas dilaut yang kondisinya sangat dinamis, ditambah kondisi gelombang laut pantai selatan yang cukup tinggi. Kecelakaan kapal yang menyebabkan nelayan meninggal dunia seringkali terjadi, bahkan kecelakaan kapal terakhir pada Juli 2018 menyebabkan 9 orang nelayan meninggal dunia. Disisi lain. mayoritas nelayan merupakan kepala keluarga yang harus menafkahi anak, istri dan keluarganya. Ketika kepala keluarga meninggal dunia, maka akan menyebabkan terjadinya masalah-masalah lain sebagai persoalan turunannya seperti kemiskinan dan lain sebagainya.

Berdasarkan diskusi yang dilakukan bersama bendahara KUB Gading Emas, akar persoalan kecelakaan kapal salah satunya disebabkan oleh diabaikannya aspek keselamatan ketika melaut mencari ikan, dimana nelayan tidak mau memakai pelampung sebagai alat keselamatan. Alasan yang dikemukakan oleh mayoritas nelayan 
adalah tidak mau direpotkan dengan pelampung pada saat aktifitas melaut. Sikap tersebut bersumber dari pengetahuan yang minim tentang pentingnya aspek keselamatan kerja. Oleh karena itu, proses penyadaran masyarakat tentang pentingnya aspek keselamatan kerja kepada nelayan menjadi sangat penting dilakukan guna meminimalisir adanya korban meninggal dunia pada saat terjadi kecelakaan kapal.

Universitas Jember telah memiliki Program Studi Teknik Konstruksi Perkapalan, oleh karena itu peran Universitas Jember sangat diperlukan sebagai bentuk pertanggungjawaban keilmuan kepada masyarakat. Sehingga dimasa mendatang jatuhnya korban jiwa pada saat terjadinya kecelakaan kapal dapat dihindari. Penyadaran akan pentingnya aspek keselamat kerja dilakukan dalam bentuk kegiatan sosialisasi kepada masyarakat nelayan melalui koordinasi dengan KUB Gading Emas. Kegiatan meliputi presentasi dan diskusi, pembagian pelampung dan simulasi secara langsung dilapangan pasca kegiatan sosialisasi guna mengetahui apakah nelayan menerapkan pengetahuan yang diberikan secara disiplin menggunakan pelampung pada saat melaut ataupun sebaliknya. Hal tersebut menjadi indikator suksesnya program pengabdian ini dan menjadi acuan untuk perencanaan program-program selanjutnya.

\section{LANDASAN TEORI}

Alat pelindung diri selanjutnya disingkat APD adalah suatu alat yang mempunyai kemampuan untuk melindungi seseorang yang fungsinya mengisolasi sebagian atau seluruh tubuh dari potensi bahaya di tempat kerja (Permenaker, 2010).

Daftar alat keselamatan perahu :

1. Pelampung penolong/life bouy

2. Jaket Penolong/Life Jacket

3. Lampu cerlang/Flashlight

4. Bucket with rope

5. Tali ikat ke kapal/Rope connected to the vessel

6. Dayung/Paddle

7. Kompas/Compass

8. Peta laut/Sea, chart/Navigation chart

9. FM Radio

10. Pemadam kebakaran/Fire extinguisher

11. Global Positioning System (GPS)

12. Radio VHF/VHF Radio

13. Mobile Phone

Untuk perahu bermesin (tambahan) :

1. Layar dan tiang layar/ sail and a mast

2. Suku cadang mesin/Spare part of the engine

3. Bahan bakar cadangan/Extra fuel of the engine

Berdasarkan Undang-undang Keselamatan Kerja N0.1. Tahun 1970, pasal 12b dan pasal 12c, bahwa tenaga kerja diwajibkan:

1. Memakai alat-alat perlindungan diri yang diwajibkan;

2. Memenuhi atau mentaati semua syaratsyarat keselamatan kerja dan kesehatan yang diwajibkan. 
Pada tingkat Internasional IMO/ILO/FAO telah mengatur standar keselamatan kapal yang berukuran $\geq 24 \mathrm{~m}$, sedangkan untuk pengaturan kapal-kapal berukuran < $24 \mathrm{~m}$ diberikan sepenuhnya kepada pemerintah setempat. Alat keselamatan di laut ditunjukkan oleh Gambar 1 .

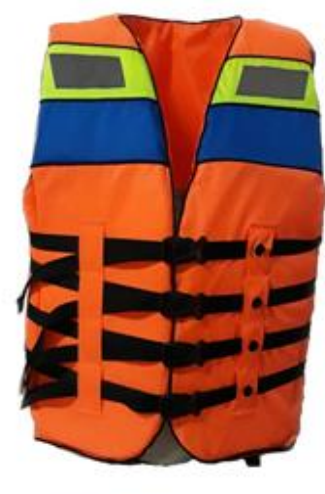

Pelampung

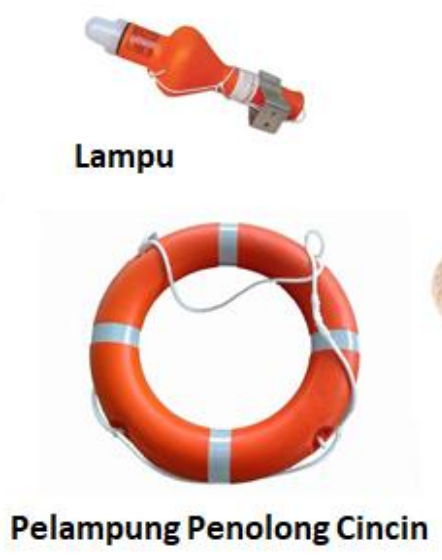

Gambar 1: APD di laut

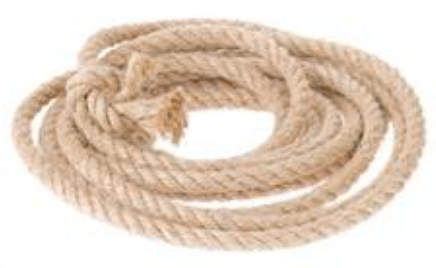

Tali Tambang

Syarat alat apung menurut SOLAS 1978 adalah sebagai berikut:

Pelampung penolong/life bouy

Pelampung yang menyelamatkan nyawa dirancang untuk dilempar kepada seseorang di dalam air, untuk memberikan daya apung dan untuk mencegah tenggelam. Diameter luar $800 \mathrm{~mm}$ dan diameter dalam $400 \mathrm{~mm}$, dibuat dari bahan apung yang menyatu, dapat mengapung 24 jam di air tawar dengan beban besi $14.5 \mathrm{~kg}$, diberi warna yang mencolok, dilengkapi dengan alat pemantul cahaya, diberi nama kapal, satu setiap perahu disimpan pada sisi kanan dek kapal.

Jaket Penolong/Life Jacket

Melindungi pengguna yang bekerja di atas air atau dipermukaan air agar terhindar dari bahaya tenggelam dan atau mengatur daya apung (buoyancy) pengguna agar dapat berada pada posisi tenggelam (negative buoyancy) atau melayang (neutral buoyant) di dalam air. Tahan dari lompatan pada ketinggian minimal $4.5 \mathrm{~m}$, harus mempunyai daya apung dan stabilitas tinggi, daya apung tidak boleh berkurang lebih dari 5\% setelah terendam dalam air tawar selama 24 jam, harus dilengkapi dengan peluit, harus mampu mengangkat muka orang dari dalam air dan menahan diatas air dengan badan terlentang dalam suatu sudut miring, harus berwarna yang mencolok/orange, nyaman pada saat pemakaian, dan satu life jacket untuk tiap orang diatas kapal.

\section{PELAKSANAAN KEGIATAN}

A. Tahap Persiapan

Proses persiapan yang dilakukan sebelum pelaksanaan kegiatan secara garis besar meliputi perencanaan teknis kegiatan dengan pihak mitra dan persiapan teknis pelaksanaan. Persiapan teknis pelaksanaan kegiatan meliputi pembelian pelampung, penyablonan pelampung dan penyusunan materi presentasi kegiatan. Pelampung dan hasil sablon ditunjukkan pada Gambar 2. 


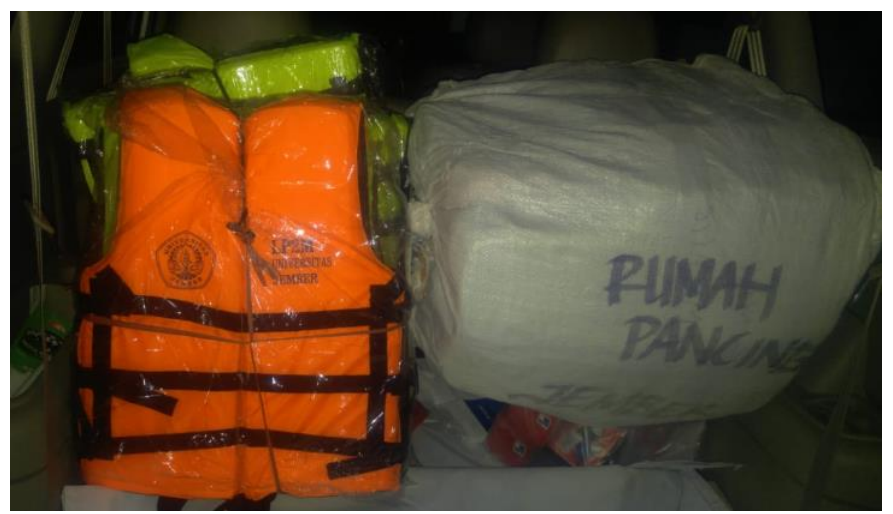

Gambar 2 : Foto Baju Pelampung dan hasil sablon

\section{B. Pelaksanaan Kegiatan}

Kegiatan sosialisasi keselamatan di laut berlangsung pada Tanggal 1 Desember 2018 bertempat di halaman kediaman Bapak Lihantoro selaku bendahara Kelompok Usaha Bersama "Gading Emas" Desa Puger Kulon Kecamatan Puger Kabupaten Jember. Kegiatan dihadiri oleh 24 orang nelayan dari unsur anggota Kelompok Usaha Bersama "Gading Emas" serta nelayan lain dari warga sekitar. Kegiatan dimulai dengan pembukaan dan sambutan dari tim pelaksana kegiatan pengabdian yang diwakili oleh Bapak Hari Arbiantara, S.T, M.T. dan dilanjutkan dengan sambutan dari ketua Kelompok Usaha Bersama "Gading Emas" Bapak Saiful Fadli. Suasana sambutan ditunjukkan oleh Gambar 3.

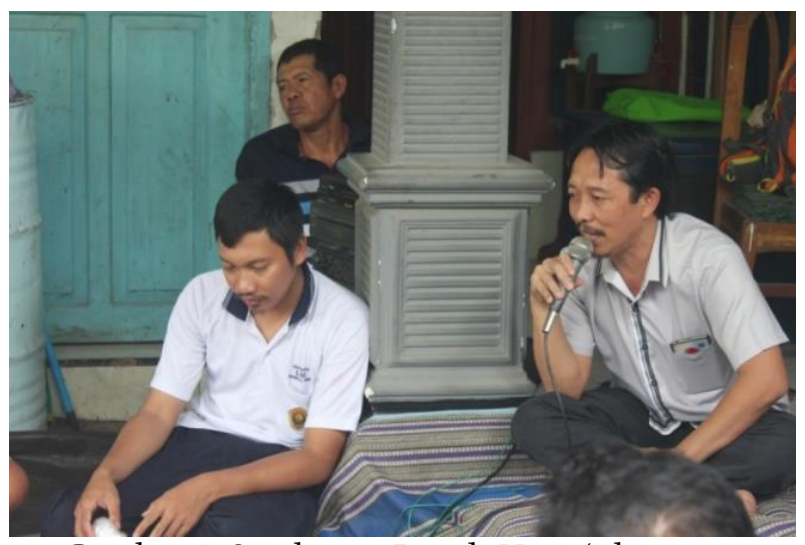

Gambar 3: Sambutan Bapak Hari Arbiantara

Selanjutnya adalah penyampaian materi presentasi oleh Muammar Kadhafi S.T, M.T selaku ketua tim pelaksana pengabdian. Suasana saat pemaparan materi ditunjukkan oleh Gambar 4. Pemaparan meliputi pengenalan alat-alat keselamatan di laut, teknik mengemudikan kapal pada kondisi ombak tinggi serta bagaiamana menyelamatkan diri apabila terjadi kecelakaan kapal. Peralatan keselamatan standar yang harus dimiliki oleh nelayan adalah baju pelampung, pluit, lampu keselamatan, pelampung lingkaran dan tali. Baju pelampung atau pelampung lingkaran digunakan agar ketika masuk ke air kondisi badan tetap mengambang diatas air. Posisi badan yang mengambang membantu nelayan agar tetap selalu dapat bernafas dengan baik di tengah laut sampai pertolongan datang. Meskipun nelayan memiliki keterampilan yang baik dalam berenang, namun kondisi laut yang dinamis tentu akan menguras tenaga dan 
semakin lama semakin habis. Selain faktor gelombang laut, arus laut juga menjadi penyebab terseretnya korban kecelakaan semakin kedalam hingga mencapai laut dalam.

Pluit digunakan agar sewaktu mengalami kecelakaan, nelayan dapat meniupnya agar didengar oleh nelayan lain yang melintas di sekitar lokasi kecelakaan atau korban kecelakaan. Pada malam hari, lampu keselamatan sangat berguna agar keberadaan nelayan yang mengalami kecelakaan dapat diketahui oleh nelayan lain yang melintas ataupun tim SAR yang melakukan pencarian dari udara maupun laut. Tali tampar selain berguna untuk membalik perahu yang terbalik, juga dapat dipakai untuk menolong korban kecelakaan kapal. Tali dapat dilempar hingga korban dapat meraihnya lalu korban dapat ditarik menuju kapal penolong.

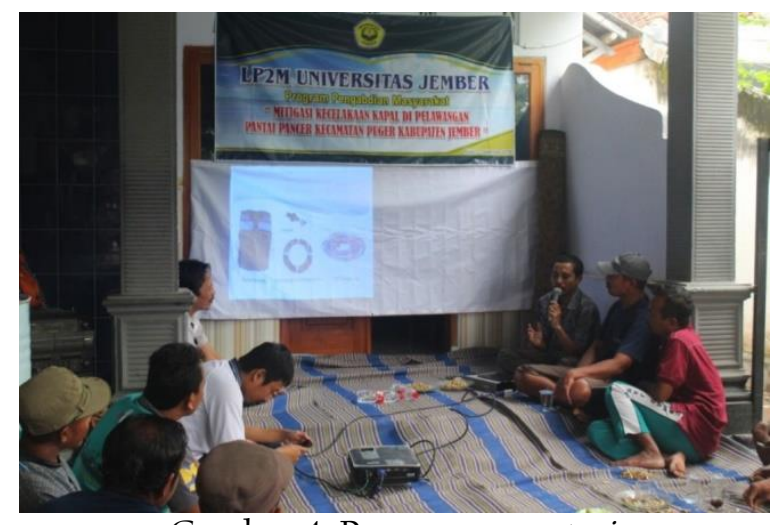

Gambar 4: Pemaparan materi

Mengemudikan kapal pada kondisi gelombang tinggi membutuhkan keterampilan dan kecermatan dari nahkoda kapal. Keselarasan antara kecepatan kapal dengan tempo periode gelombang harus diperhatikan secara seksama oleh nahkoda. Dan yang terpenting dan harus dilakukan oleh nahkoda adalah selalu mengarahkan kapal tegak lurus terhadap arah datang gelombang. Umumnya kecelakaan kapal yang terjadi di Pelawangan Puger hingga kapal terbalik karena posisi kapal tidak tegak lurus terhadap arah datang gelombang. Saat kapal mulai berbelok lalu gelombang menghantap dari samping maka seketika kapal kehilangan keseimbangan lalu terbalik.

Proses sosialisasi berlangsung dinamis dengan dibukanya sesi diskusi antara tim pelaksana dengan peserta pengabdian. Sesi diskusi dimoderatori oleh Bapak Mochamad Edoward Ramadhan, S.T., M.T. selaku anggota tim pelaksana. Diskusi diawali penyampaian permasalahan yang dihadapi dilapangan oleh ketua KUB. Dalam penyampaian tersebut dipaparkan bahwa persoalan utama adalah minimnya kesadaran individu terkait aspek keselamatan di laut. Profesi nelayan di Puger terbagi kedalam dua kelompok yaitu nelayan yang memiliki perahu pribadi dengan ukuran perahu kecil dan nelayan pekerja dimana mereka menjadi buruh untuk pemilik kapal kayu berukuran besar. Tuntutan ekonomi mengharuskan para nelayan pekerja untuk tetap melaut meskipun kondisi cuaca sedang tidak bagus karena harus mengikuti keinginan pemilik kapal. Disisi lain para pekerja tersebut tidak dibekali dengan alat keselamatan yang memadai. Para nelayan juga menyampaikan masukan agar pihak Universitas Jember juga mengadakan sosialisasi yang sama bagi para pemilik kapal agar juga memperhatikan aspek keselamatan pekerja di laut. Suasana sesi diskusi dapat dilihat pada Gambar 5. 
Persoalan lain yang dikeluhkan oleh masyarakat nelayan adalah agar pihak pemerintah segera melakukan perbaikan terhadap bangunan pantai pemecah gelombang yang ada di Puger. Perilaku gelombang menjadi kacau dan susah diprediksi oleh para nelayan akibat perubahan arah gelombang setelah melewati pemecah gelombang. Disisi lain pemecah gelombang sendiri mengalami kerusakan yang sangat parah sehingga perlu dilakukan studi ulang dan pembangunan ulang.

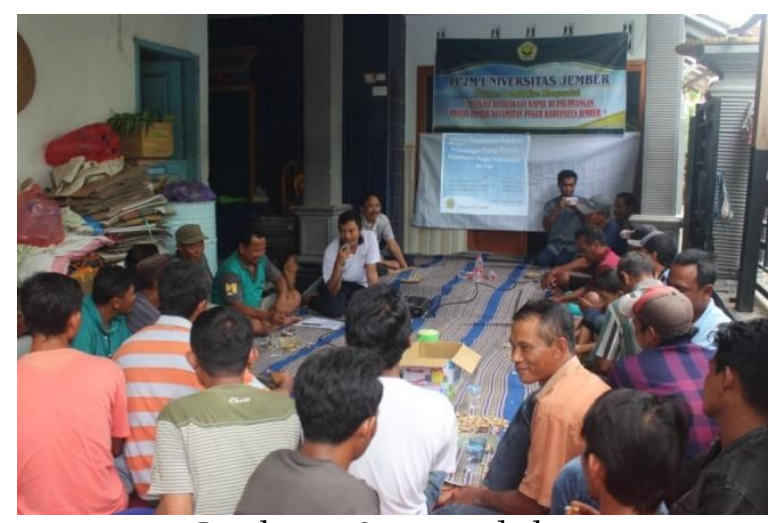

Gambar 5: Suasana diskusi

Acara sosialisasi diakhiri dengan makan bersama yang dilanjutkan dengan serah terima alat keselamatan dari tim pelaksana kepada ketua KUB. Peserta menyampaikan ucapan terimakasih dan apresiasi kepada tim pelaksana serta berharap kegiatan ini dapat berlanjut untuk kedepannya karena sangat bermanfaat dalam meningkatkan pemahaman nelayan khususnya dalam aspek keselamatan. Suasana makan bersama dapat dilihat pada Gambar 6 sedangkan proses serah terima alat keselamatan dapat dilihat pada Gambar 7.

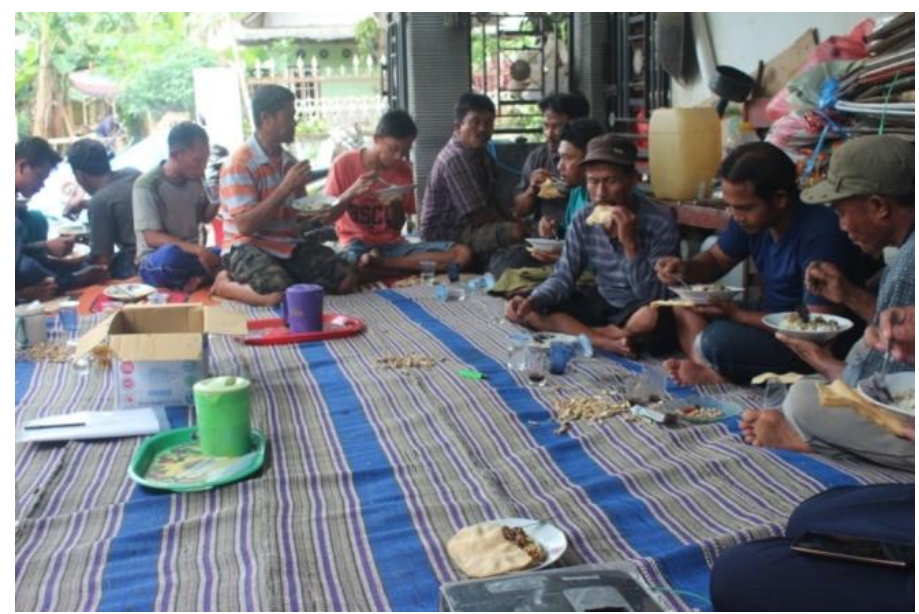

Gambar 6: Suasana makan bersama 


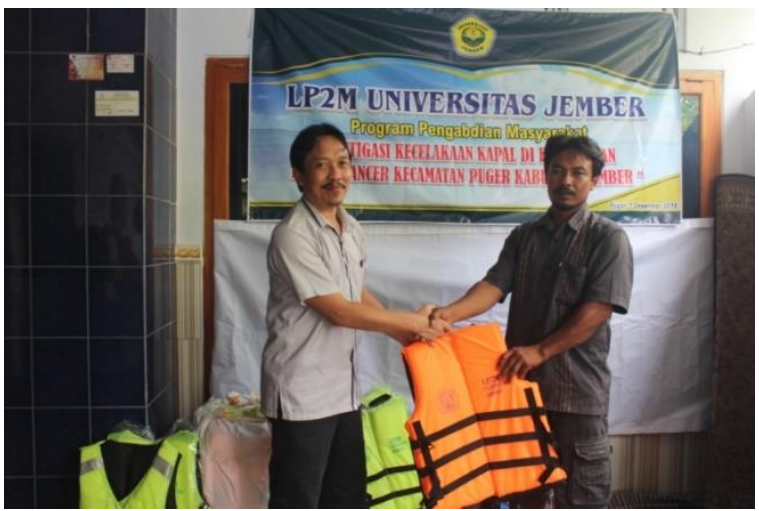

Gambar 7: Serah terima alat

\section{Monitoring}

Dalam rangka memastikan penerapan pengetahuan dan peralatan keselamatan yang telah diberikan, maka dilakukan proses monitoring yang sebelumnya didak diberitahukan kepada nelayan pada lokasi pengabdian. Hasil monitoring menunjukan bahwa sebagian nelayan telah memiliki kesadaran untuk menggunakan alat keselamatan sedangkan sebagian yang lain masih perlu diingatkan. Untuk itu tim pelaksana pengabdian berpesan kepada segenap anggota KUB untuk senantiasa saling mengingatkan antara sesama nelayan guna selalu menggunakan alat keselamatan pada saat melaut terutama pada saat melewati pintu pelawangan sebagai tempat yang rawan terjadinya kecelakaan kapal.

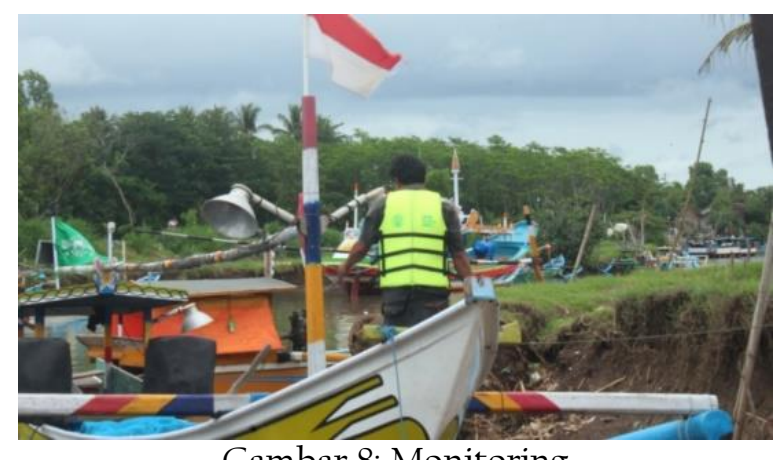

Gambar 8: Monitoring

IV. PEMBAHASAN

Peraturan-peraturan yang berlaku bertujuan untuk melindungi seseorang dari bahaya, tetapi masyarakat nelayan tidak terlalu mengkhawatirkannya. Hal ini dikarenakan kurangnya pendidikan tentang keselamatan kerja sehingga mereka merasa bahwa keselamatan tidak menjadi prioritas utama dalam pekerjaan di laut.

Menurut data yang didapatkan, armada kapal perikanan berukuran kecil (panjang kapal < $24 \mathrm{~m}$ ) belum banyak diatur oleh pemerintah sementara jumlah kapal berukuran kecil mendominasi armada industri perikanan tangkap nasional, yakni mencapai 94\% dari total armada kapal penangkap ikan (DKP, 2009). Belum adanya peraturan khusus tentang keselamatan kapal-kapal kecil menunjukan bahwa keselamatan nelayan dalam kegiatan penangkapan di Indonesia sampai saat ini belum diperhatikan dan belum ada kebijakan yang jelas dari pemerintah daerah dan pusat. Belum diterapkannya pengaturan tentang kepelautan kapal perikanan, serta belum tersedianya standar kapal penangkap ikan, standar alat keselamatan, standar operasi, 
standar pengawakan kapal dan standar keterampilan awak kapal menjadi masalah utama dalam pengembangan perikanan di Indonesia..

\section{KESIMPULAN DAN SARAN}

Dari kegiatan pengabdian masyarakat ini dapat disimpulkan bebrapa hal antara lain sebagai berikut:

a. Upaya penyadaran terhadap masyarakat nelayan akan pentingnya keselamatan di laut harus dilakukan secara terus-menerus melalui keberadaan Kelompok Usaha Bersama setempat.

b. Keterbatasan sarana alat-alat keselamatan menjadi kendala mengingat alat keselamatan seperti pelampung memiliki life time tertentu, sehingga dapat mengalami kerusakan.

c. Universitas Jember berperan aktif dalam upaya mitigasi kecelakaan kapal sebagai kontibusi keilmuan terlebih Universitas Jember telah memiliki Prodi Teknik Perkapalan.

Adapun saran dari tim pelaksana, reviewer monev serta dari warga nelayan adalah sebagai berikut:

a. Kegiatan pengabdian diharapkan dapat berlanjut dengan skim multitahun sehingga persoalan mitigasi ini dapat secara tuntas diselesaikan.

b. Selanjutnya agar melibatkan pemilik kapal besar dalam kegiatan pengabdian masyarakat ini, sehingga memiliki presepsi yang sama dengan para nelayan pekerja.

c. Mengusulkan kegiatan pengabdian ini ke skim yang lebih tinggi melalui simlibtabmas.

\section{DAFTAR PUSTAKA}

Kingsbury, Damien \& Leena Avonius, eds. Human Rights in Asia: A Reassessment of the Asian Values Debate (New York: Palgrave Macmillan, 2008).

SOLAS. 1978. International Convention the Safety of Life at Sea.

Danielson Per. 2004. Small Vessel Safety Review. SSPA Report 2002 2798. SSPA Sweden AB.

Adi Guna Santara. 2014. Safety Equipment on Slerek in Pengambengan Nusantara Fishing Port, Jembrana, Regency, Bali.

Suma'mur. 1996. Keselamatan Kerja dan Pencegahan Kecelakaan. CV. Haji Masagung. Jakarta. 